\title{
CLINICAL AND HISTOPATHOLOGICAL STUDY OF IMPORTANT AIR-BREATHING FISHES
}

\author{
Z. P. Patwary, M. A. R. Faruk and M. M. Ali \\ Department of Aquaculture, Bangladesh Agricultural University \\ Mymensingh-2202, Bangladesh
}

\begin{abstract}
A study was conducted to know the health and disease problems of three important air-breathing fishes viz. Shing (Heteropneustes fossilis), Magur (Clarias batrachus) and Thai Koi (Anabas testudineus) through clinical and histopathological technique from June 2007 to March 2008 collected from selected farms and from local markets. Generally, during December and January, acute pathologies were recorded. Clinical signs of Shing included haemorrhage, extended belly and ulceration. Histopathologically, partly missing and splitted epidermis and dermis, necrotic, vacuoled and ruptured myotomes of muscle with fungal granuloma were observed. Major gill pathologies included partly missing and highly hypertrophied, haemorrhagic gill lamellae, presence of monogenetic trematode and pyknotic cells. In liver, haemorrhagic areas, necrotic, vacuoled, hyperplasid hepatocytes, cell debris, pyknotic nuclei and plenty of inflammatory cells were evident. Haemorrhages, vacuolation, necrosis, missing and ruptured kidney tubules and pyknotic nuclei were the major pathologies of kidney. Clinically, dark red lesion, haemorrhage, necrosis and ulcer in body surface were seen in Magur. Histopathologically observed pathologies in Magur were almost similar to that of Shing. Clinical signs of Thai Koi included discoloration, loss of scales and fins, abnormal caudal fin, haemorrhage in gill and ulcer. Marked histopathology in the skin and muscle were observed such as totally lost epidermis, dermis separated from muscle, severely ruptured, degenerated and missing of myotomes in many places. In gills, hypertrophy, hyperplasia, telangiectasis, clubbing, haemorrhage and massive necrosis in both primary and secondary gill lamellae were found. Pathologies observed in liver and kidney were most alike to that of Shing. In the months of February and March, all the investigated organs of the three fish species were at a healing stage.
\end{abstract}

Key words : Air-breathing fishes, Health and disease, Clinical signs, Histopathology

\section{INTRODUCTION}

In Bangladesh, air-breathing fishes like Koi (Anabas testudineus), Magur (Clarias batrachus), Shing (Heteropneuetes fossilis), Shoal (Channa striatus) and Taki (Channa punctatus) are very favorite and popular due to tender meat and delicious taste. These fish have very good market demand and they command higher and more lucrative price than Indian major carps and other table fishes. Air-breathing fishes are those which have evolved methods 
of extracting oxygen from air. Once easily available in almost all freshwater areas of the country, in recent days the availability of these fishes has drastically declined due to many reasons and one of the most important reasons is the outbreak of various types of diseases. Considering the culture potentials of these fishes very recently, a sharp increasing trend has observed on Shing, Magur and Koi, especially Thai Koi culture in Bangladesh.

Prevalence of disease is considered as one of the major reasons for poor fish production of the country. With the expansion of air-breathing fish culture, there are reports of diseases of these fish under culture condition. Hasan (2007) reported that an established Shing fish farm was found to be heavily affected by ulcer type disease in Mymensingh area and by investigation, Aeromonas hydrophila were isolated from the lesion. During the outbreaks of EUS in the late 1980s, the air-breathing indigenous fishes were found to be the most severely affected species (Barua et al., 1989; Roberts et al., 1994; Lilley et al., 1998). As a result, their availability in the market declined sharply and in fact their existence appeared to be threatened over years. They are still very vulnerable to EUS and if this situation continues, these fishes will be endangered in the near future. At the same time, it will imbalance the biodiversity. The clinical signs and histopathology are very helpful in diagnosing fish disease.

Knowledge on the disease pattern in air-breathing fishes is essential for developing their culture technology. However, there is a severe lack of information on the diseases of airbreathing fishes. Considering the above fact the present study has been undertaken to investigate diseases in three commercially important air-breathing fishes, stinging catfish, walking catfish and climbing perch. The specific objectives of the present study were i.) to examine health and disease condition of air-breathing fishes, Shing, Magur and Thai Koi through clinical and histopathological technique and ii.) to determine the histopathological changes of the fish tissues due to diseases.

\section{MATERIALS AND METHODS}

The study was consisted of both clinical observations and laboratory analysis.Fish samples were collected from 2 different fish farms (Agro Three Farm Ltd. and Reliance Aqua Farm, Trisal, Mymensingh) in every 15 days interval during the experimental period. One pond was selected from each farm and five fishes were collected randomly in each sampling point for investigation. In addition, diseased fishes were collected from 2 markets (K-R Market, BAU and Machchya Bazar, Mymensingh Town). After collection, live fishes were immediately carried to the Fish Disease Laboratory of the Faculty of Fisheries, BAU, Mymensingh.

The sampled fishes were examined to observe external signs and record any injury, infection and other abnormal conditions of fish body through naked eye. For histopathological observations samples from various organs of fish such as skin, muscle, gills, liver and kidney were collected by a sharp scalpel and forceps and fixed in $10 \%$ neutral buffered formalin. Size of the samples was $1 \mathrm{~cm}^{3}$. The fixed samples were taken out and placed in an automatic tissue processor machine (Shandon, Citadel 1000) for 
dehydration, clearing and wax infiltration. After tissue processisng (21 hours), the samples were embedded with melted wax, perforated plastic holder and steel mold. Then sections were taken from the blocks at a thickness of 5 micrometers by using the microtome machine (Leica Jung RM 2035). The sections were then stained with haematoxyline and eosin stains. After staining, the sections were mounted with Canada balsam and covered by cover slips. The prepared sections were left over a clean platform to hold the cover slips permanently and then examined under a compound microscope (Olympus). Photomicrograph of the stained sections was done by using a photomicroscope (Olympus, Model CHS, Japan).

\section{RESULTS AND DISCUSSION}

\section{Clinical observations}

\section{Shing (Heteropneustes fossilis)}

Clinically, Shing was healthy and almost normal in appearance on the threshold of the investigation. However, in the later part of the study, fishes were found to be with weak body, rough skin, haemorrhage, ulcer in whole body and extended belly (Fig. 1). Sahoo et al. (1998) reported that in an outbreak of ulcer disease in an organised farm, $10 \%$ of catfish (H. fossilis) population showed round ulcers on body surface. This result is more or less similar to the present finding.

\section{Magur (Clarias batrachus)}

In the months of June, July, August, February and March, Magur was observed clinically normal and healthy in their appearance. In September and October, less clinical signs were found. On the other hand, during November to January, clinically weak body, rough skin, dark red lesion all over the body including head, haemorrhage in dorsoventral and caudal region, caudal fin loss, ulcer and haemorrhage in the jaw, ventral body surface and at the base of the fins (Fig. 2) were seen. Similar pathological conditions were observed by Nessa (2000), Khatun (1999) and Ruksana (1998) for Magur obtained from open water bodies of Bangladesh. They observed deep red necrosis, loss of skin and haemorrhagic lesions which turned into ulcer at dorsoventral and caudal regions of the fish.

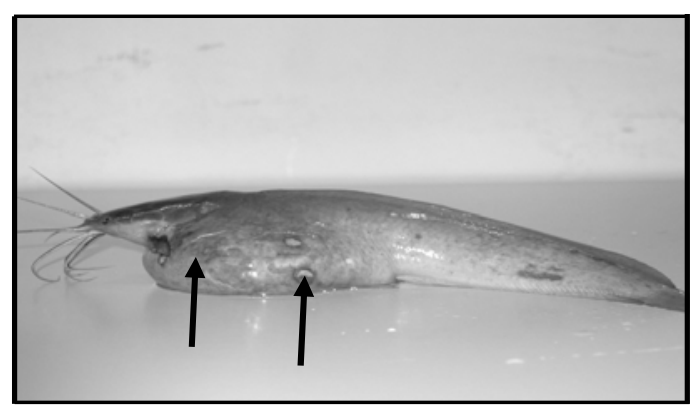

Fig. 1. Diseased Shing having extended belly with ulcerative lesion collected in December

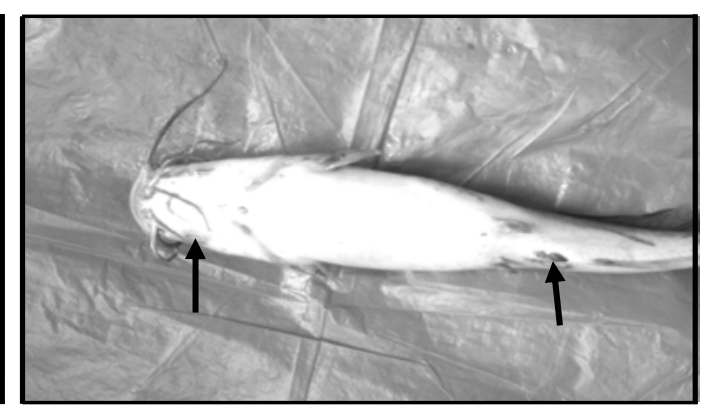

Fig. 2. Diseased Magur having haemorrhag -e in the jaw, ventral body surface and at the base of fins in January 


\section{Thai Koi (Anabas testudineus)}

Thai Koi was apparently healthy and almost normal at the beginning of the study. However, during October to January, the recorded clinical signs were discoloration, rough skin, weak body, deep ulcer and loss of scales (Fig. 3) and fins, abnormal caudal fin, thickness of gill filament, haemorrhage in gill, haemorrhage and ulcer in the dorsoventral and caudal region (Fig. 4). These findings were almost similar with the findings of Dhar (2007), Kulsum (2005), Chakma (2002) and Muniruzzaman (2000). Dhar (2007) found rough skin, scale loss, haemorrhage with reddish bright spots, deep ulcer at dorsoventral region in Thai Koi.

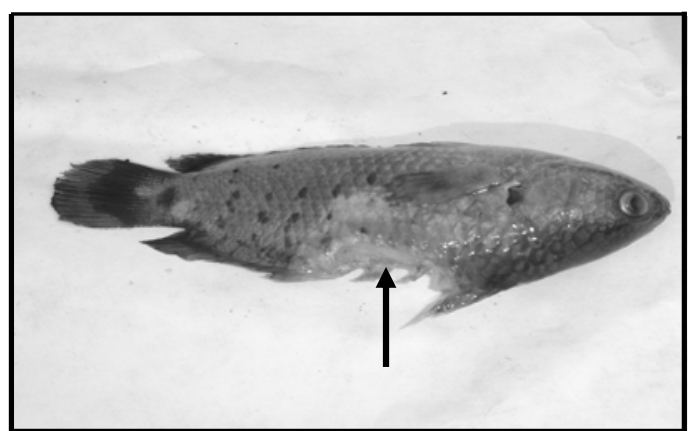

Fig. 3. Diseased Thai Koi having deep ulcer with scale loss in December

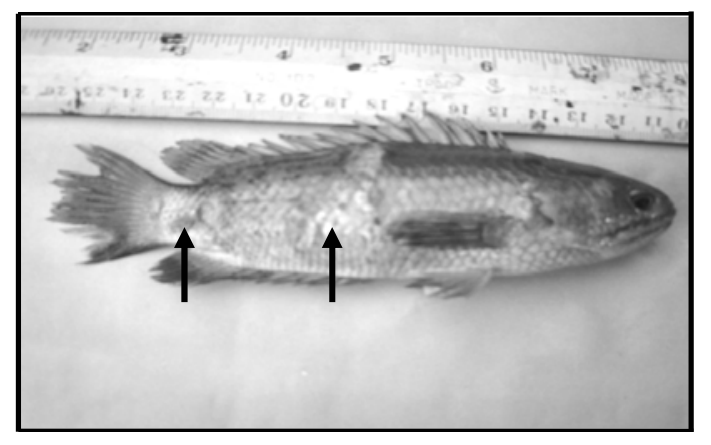

Fig. 4. Diseased Thai Koi having ulcer all over the body and caudal fin loss in January

\section{Histopathological observations}

\section{Shing (Heteropneustes fossilis)}

It was observed histopathologically that skin and muscle, gill, liver and kidney structure of Shing, $H$. fossilis were almost normal in the months of June, July, August, September, February and March. On the contrast, during the period of October to January, pathological changes were observed in skin and muscle, gill, liver and kidney. Partly missing epidermis, epidermis and dermis splitted from muscle (Fig. 5), severely affected, necrotic, vacuoled and ruptured myotomes of muscle with fungal granuloma were observed pathological signs in skin and muscle of Shing. Ahmed (1990) reported that excess mucous secretion or loss of cuticle layer could be considered as stressed or diseased condition. This research finding is almost similar to the present study.

Tips of the secondary gill lamellae were swollen, missing secondary gill lamellae, highly hypertrophied, haemorrhagic both primary and secondary gill lamellae (Fig. 6), presence of monogenetic trematodes and pyknotic cells were the pathological signs observed in gill of Shing, H. fossilis. Roy et al. (2006) reported that cysts, hyperplasia, lamellar clubbing and hypertrophy were observed in EUS affected Channa punctatus, Mystus tengra and $H$. fossilis. This result is closer to the present findings.

In liver of $H$. fossilis, observed pathologies included haemorrhagic areas, inflammatory cells (Fig. 7), necrotic, vacuoled and hyperplasid hepatocytes, cell debris and presence of 
pyknotic nuclei. Joshi et al. (2007) observed the histopathological changes in liver of $H$. fossilis ranged from vacuolization, necrosis, fibrosis of perivascular region and disposition of yellow brown grains exposed to cypermethrin. This finding is more or less parallel to the present investigation.

In this study, in the structure of kidney of $H$. fossilis, recorded pathological signs were haemorrhage, vacuolation (Fig. 8), necrosis, missing and ruptured kidney tubules and pyknotic nuclei and blood cells were scattered throughout the kidney. Islam (2006) found tissue abscess characterized by focal necrosis, haemorrhage and vacuolation in the kidney of experimentally infected Shing with Aeromonas hydrophila. This finding is almost alike the present study.

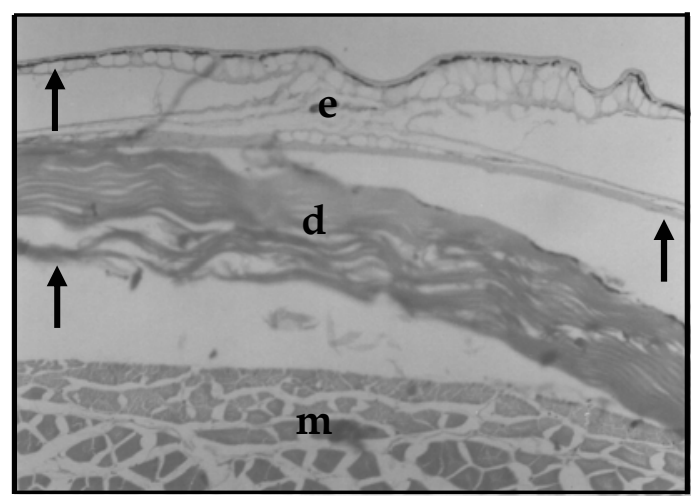

Fig. 5. Epidermis (e) and dermis (d) separated from muscle $(\mathrm{m})(\uparrow)$ found in November Haematoxylin and eosin x 120 .

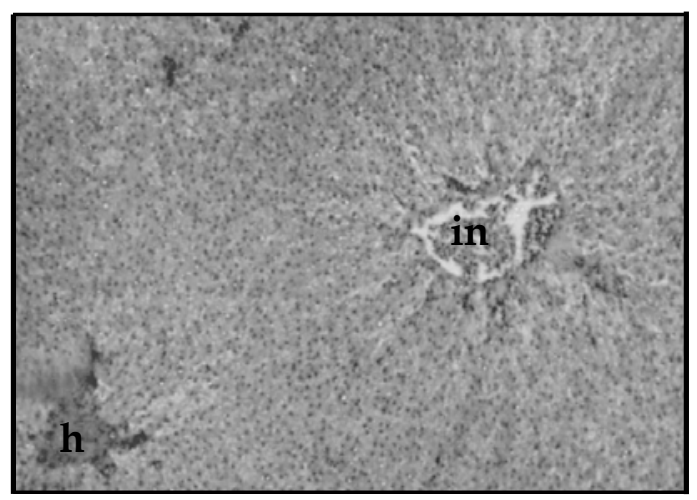

Fig. 7. Almost normal liver with mild haemorrhage $(\mathrm{h})$ and inflammatory cyst (in) in November. Haematoxylin and eosin $x 120$

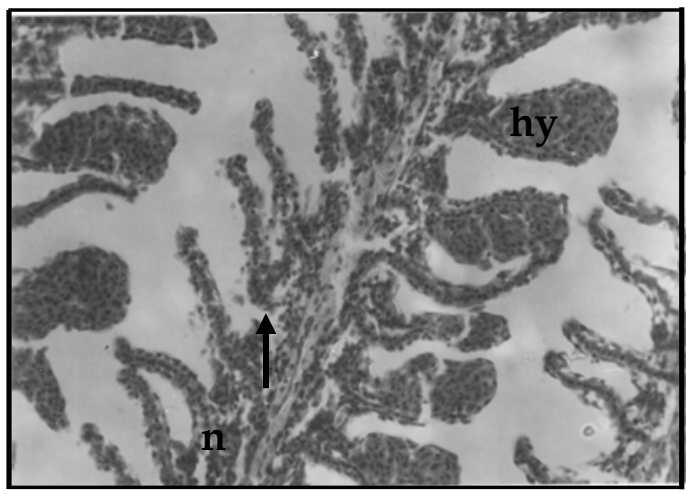

Fig. 6. Highly hypertrophied (hy) and partly separated secondary gill lamellae $(\uparrow)$ and severe necrosis (n) in both primary and secondary gill lamellae were seen in December. Haematoxylin and eosin $\times 480$.

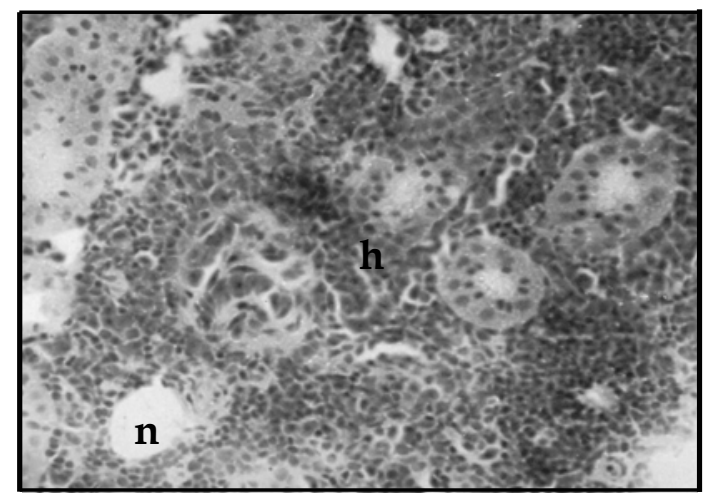

Fig. 8. Kidney tubules having large vacuoles (v) and haemorrhage (h) all over in December. Haematoxylin and eosin $x 480$ 


\section{Magur (Clarias batrachus)}

Histopathologically, less pathological signs in skin and muscle, gill, liver and kidney of C. batrachus were observed in the months of June, July, August, September, February and March. During the period of October to January, severe pathologies were seen in skin and muscle, gill, liver and kidney. Epidermis and dermis separated from muscle, severely ruptured, necrotic and vacuoled myotomes of muscle with fungal granuloma (Fig. 9) were observed in skin and muscle histopathologically. From the research findings of Ruksana (1998), it was observed that epidermis was totally lost, dermis was partly lost and myotomes of muscles were severely affected in catfish (Clarias batrachus) during January. Nessa (2000); Khatun (1999) were also observed similar pathologies in C. batrachus. They found histopathologically, loss of skin epidermis, ruptured dermis and muscle and necrosis with vacuolation, fungal granuloma in skin and muscle of the affected fishes.

Haemorrhage, hypertrophy, hyperplasia, clubbing and massive necrosis in the both primary and secondary gill lamellae (Fig. 10), tips of secondary gill lamellae were swollen and secondary gill lamellae were lost in many places and presence of monogenetic trematodes and pyknotic nuclei were the observed pathologies in gill of C. batrachus. Nessa (2000); Khatun (1999); Ruksana (1998) found a marked hyperplasia, hypertrophy, numerous inflammatory cells and haemorrhagic lesions in both primary and secondary gill lamellae, missing of part or whole secondary gill lamellae. These findings are more or less closer to the present study.

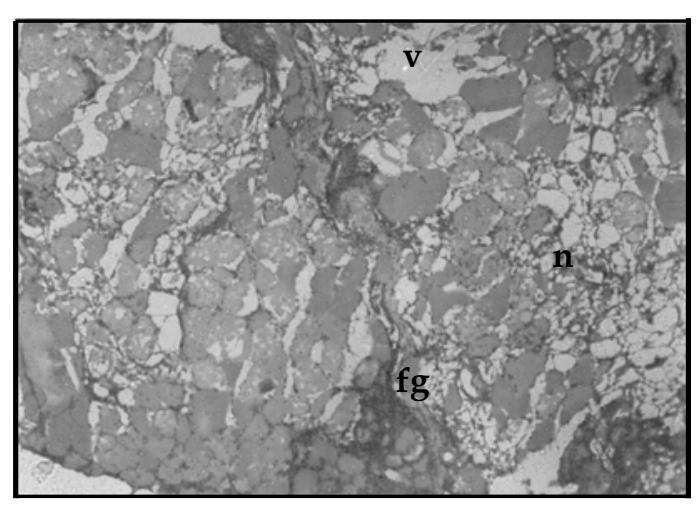

Fig. 9. Severely necrotic (n) and vacuoled (v) and ruptured myotomes of muscle with fungal granuloma (fg) in January. Haematoxylin and eosin $\times 120$

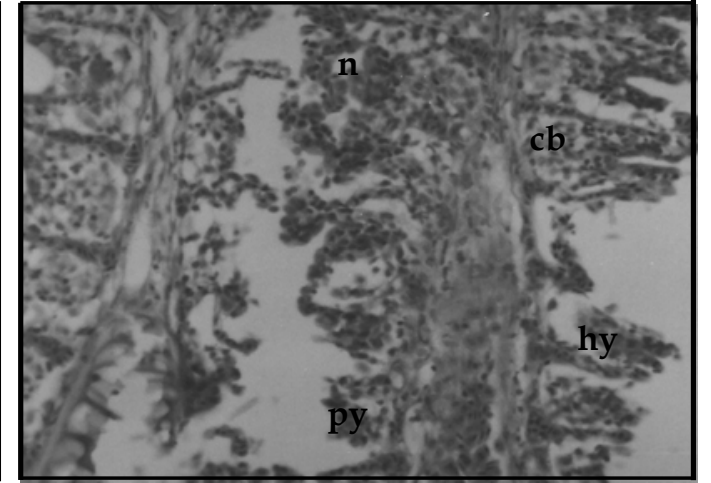

Fig. 10. Highly hypertrophied (hy) primary gill lamellae and massive necrotic (n) primary and secondary gill lamellae with clubbing (cb) and pyknotic cells (py) in December. Haematoxylin and eosin x 480

Marked pathological changes were also found in the internal organs of $C$. batrachus such as liver which include marked necrosis, haemorrhage, pyknotic nuclei (Fig. 11), blood cells, numerous fat body, vaccums and hepatocytes missing in some places. Nessa (2000); Khatun (1999); Ruksana (1998) also observed similar liver pathology. They observed 
necrosis, hypertrophy and vacuoles and haemorrhage in some places of liver of $C$. batrachus.

Kidneys were severely affected and ruptured and missing kidney tubules in some places, necrosis, parasitic cysts, large vacuoles (Fig. 12), severe haemorrhage and presence of melanomacrophage center, and pyknotic cells were the pathological changes in C. batrachus. From the research findings of Nessa (2000), Khatun (1999) and Ruksana (1998), similar pathologies were found in kidney of C. batrachus. They found that kidney tubules, blood cells, renal corpucles and haematopoietic tissuewere ruptured and necrotic having small vaccum, blood cell, protozoan cyst and fungal granuloma.

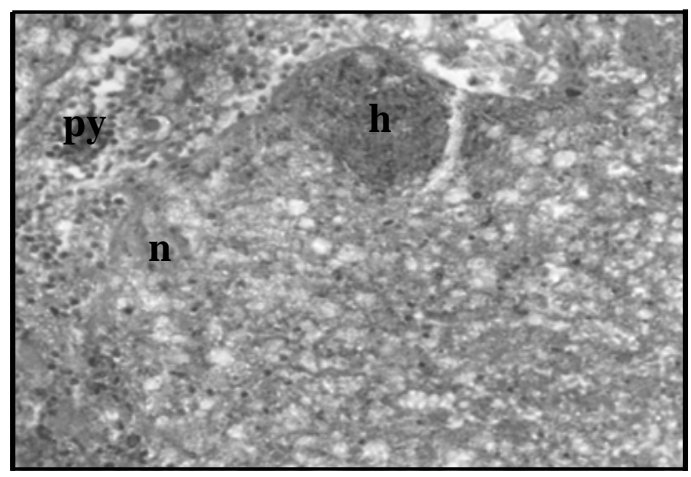

Fig. 11. Mild haemorrhage (h) and necrotic (n) hepatocytes with pyknotic cells (py) were seen in liver in November. Haematoxylin and eosin $\times 120$

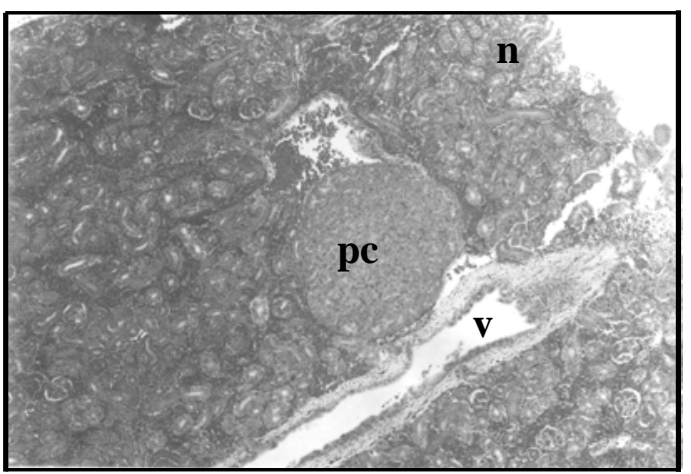

Fig. 12. Degenerated kidney tubules with large parasitic cyst (pc), necrosis (n) and vacuoles (v) in January. Haematoxylin and eosin $\times 120$

\section{Thai Koi (Anabas testudineus)}

Under histopathological observations, skin and muscle, gill, liver and kidney of Thai Koi were recorded almost normal in their arrangements in the months of June and July. Less pathological changes were observed in August. Marked pathological changes were observed in September and October. Severity of pathologies in skin and muscle, gill, liver and kidney were gradually decreased in February and March. However, during November to January severity of infections were more prominent. Histopathologically, in the skin and muscle, totally lost epidermis, dermis separated from muscle (Fig. 13), myotomes were severely ruptured, degenerated and missing in many places. Kulsum (2005) also found missing of skin epidermis, ruptured myotomes, necrotic muscle, pyknotic cells, vaccums and parasitic cysts in the skin and muscle of Thai Koi. This finding is almost analogous with the present study.

Gills exhibited pathological changes, which include hyperplasia, talengiectasis, hypertrophy, clubbing, haemorrhage, massive necrosis in both primary and secondary gill lamellae (Fig. 14) and missing of secondary gill lamellae during November to 
January. Dhar (2007) also observed marked hypertrophy and hyperplasia in primary gill lamellae, protozoan cysts and necrosis in secondary gill lamellae during December and January in Thai Koi. This finding is more or less similar with the present study.

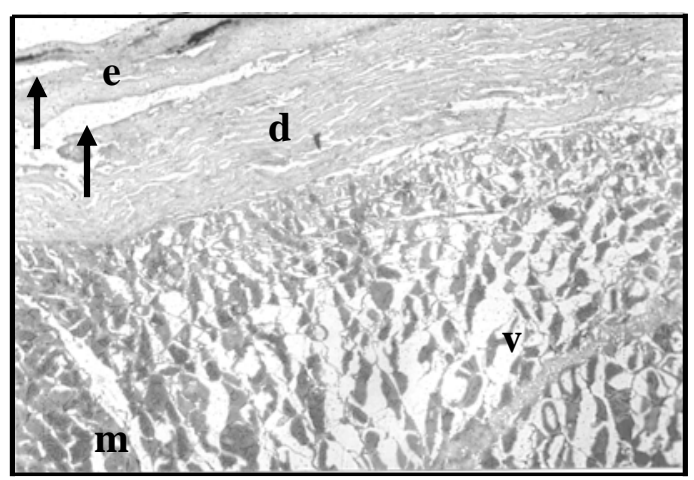

Fig. 13. Epidermis (e), dermis (d) separated $(\uparrow)$ from muscle (m) with vacuoles (v) found in September. Haematoxylin and $\operatorname{eosin} \times 120$

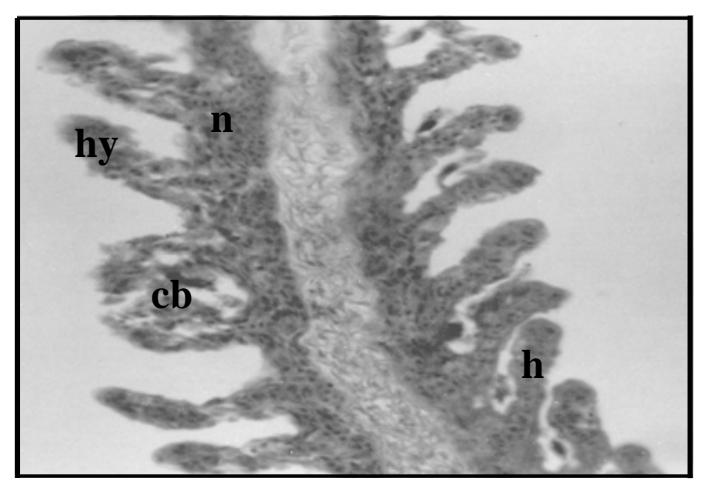

Fig. 14. Haemorrhage (h), hypertrophy (hy) and clubbing $(\mathrm{cb})$ in secondary gill lamellaeand necrosis (n) in primary gill lamellae in Novemver. Haematoxylin and eosin $x 480$

In the present experiment, severely affected hepatocytes having necrosis, vacuoles, fungal granuloma, haemorrhagic lesions (Fig. 15) and presence of pyknotic cells were important pathological symptoms observed in Thai Koi liver. Kulsum (2005); Chakma (2002); Moniruzzaman (2000) also observed similar liver pathology in A. testudineus. They observed liver to be highly necrotic, pyknotic and haemorrhaged. They also found fungal granuloma and vacuolation in the liver of Koi from Mymensingh district.

Pathologies were found to be started with mild haemorrhage and vacuolation in the kidney of Thai Koi. Kidney tubules were ruptured and degenerated, haemorrhagic, necrotic and vacuoled with melanomacrophage center (Fig. 16), pyknotic nuclei and inflammatory cells at later part of the study. Similar observations were found by Chakma (2002); Hussain et al. (2002); Moniruzzaman (2000). Chakma (2002); Moniruzzaman (2000) observed necrosis, pyknosis, haemorrhage and blood cells in the kidney of Koi. Hussain et al. (2002) found degenerative changes like necrosis of tubular and haematopoietic cells of kidney.

The present study revealed that external organs such as skin and muscle and gill were more affected than the internal organs like liver and kidney. Observed severity of pathologies was abridged in both the farms in comparison to both the fish markets for Shing, Magur and Thai Koi. 


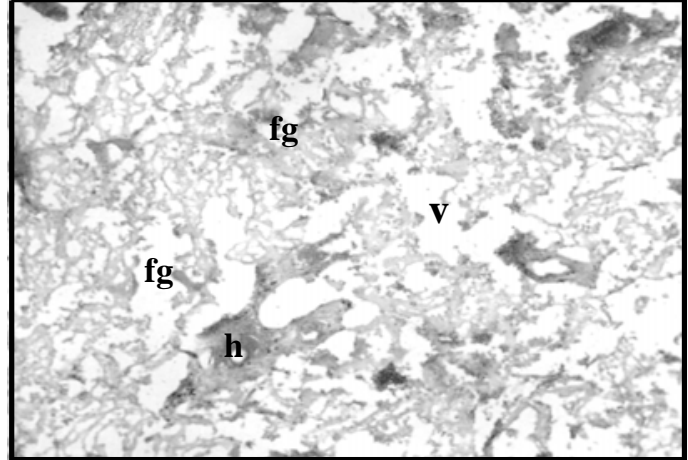

Fig. 15. Severely affected hepatocytes having necrosis (n), vacuoles (v) and haemorrahagic (h) lesions with huge fungal granuloma (fg) found $n$ December. Haematoxylin and eosin $\times 120$

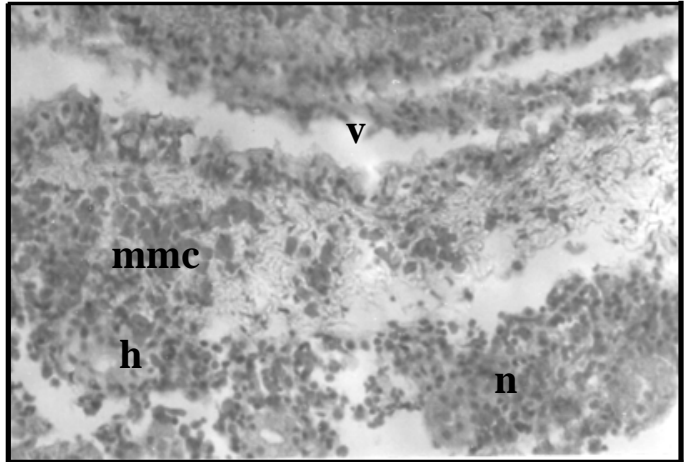

Fig. 16. Ruptured and degenerated kidney tubules with haematopoietic necrosis, haemorrhage (h), melanomacrophage center (mmc) and vacuoles (v) in December. Haematoxylin and eosin $x 120$

Results of the present study indicated that apparently normal structure was observed both clinically and histopathologically during June to September and in the months of October and November, fewer pathologies were observed in all the three species. However, in the months of December and January, acute pathologies were recorded both clinically and histopathologically in case of all the three species. Barua (1994) also made similar opinion that fish under stress from environmental changes usually do not want to eat, become weak and more susceptible to disease. Similarly in the present study, infections were increased in December and January. Conversely in the months of February and March, all the investigated organs of the three fish species were at a healing stage which was confirmed by both clinical and histopathological observations. The process of healing could be due to gradual increase of temperature during this period.

\section{REFERENCES}

Ahmed, G. U. 1990. The responses of the skin of the catfish, Clarias macrocephalus, in relation to intensive fish farming. Ph.D. Thesis, School of Biological Sciences. University Sains Malaysia. Penang, Malaysia. $304 \mathrm{p}$.

Barua, G. 1994. The status of epizootic ulcerative syndrome of fish of Bangladesh. In: Roberts, R. J., B. Campbell and I. H. MacRae (eds.), Proceedings of the ODA regional seminar on epizootic ulcerative syndrome, 25-27 January 1994. pp. 13-20. Aquatic Animal Health Research Institute, Bangkok.

Barua, G., Banu, A. N. H. and Khan, M. H. 1989. An investigation into the prevalence of fish disease in Bangladesh during 1988-1989. Bangladesh J. Aquacult., 11(2): 75-79.

Chakma, A. P. 2002. Histopathological observation on the effect of potassium permanganate in curing diseased small indigenous fishes. M. S. Thesis, Department of Aquaculture, Bangladesh Agricultural University, Mymensingh, Bangladesh. 65 pp. 
Dhar, M. 2007. Investigation of health status of Thai koi, Anabas testudineus (Bloch) from farming conditions. M. S. Thesis, Department of Aquaculture, Bangladesh Agricultural University, Mymensingh. 60 pp.

Hasan, M. A. 2007. Pathogenicity of Aeromonas hydrophila in EUS like disease affected Heteropneustes fossilis. M. S. Thesis, Department of Aquaculture, Bangladesh Agricultural University, Mymensingh. 64 p.

Hussain, Z., Rahman, M. Z. and Mollah, M. F. A. 2002. Effect of dimecron 100SCW on Anabas testudineus, Channa punctatus and Barbodes gonionotus. Indian J. Fisheries., 49 (4): 405-417.

Islam, M. T. 2006. Histopathogical studies of shing Heteropneustes fossilis experimentally infected with the bacterial pathogen Aeromonas hydrophila. M. S. Thesis, Department of Aquaculture, Bangladesh Agricultural University, Mymensingh. 54 pp.

Joshi, N., Dharmlata and Sahu, A. P. 2007. Histopathogical changes in liver of Heteropneustes fossilis exposed to cypermethrin. J. Environ. Biol., 28(1): 35-37.

Khatun, A. 1999. Monthly histopathological investigation of disease in Clarias batrachus (Linn.) in Mymensingh area. M. S. Thesis, Department of Aquaculture, Bangladesh Agricultural University, Mymensingh. 64 pp.

Kulsum, U. 2005. Culture status and disease investigation of Thai koi (Anabas testudineus) in some selected upzilas of Mymensingh district. M. S. Thesis. Department of Aquaculture, Bangladesh Agricultural University, Mymensingh. 62 pp.

Lilley, J. H., Callinan, R. B., Chainabut, S., Kanchanakhan, S., MacRae, I. H. and Philips, M. J. 1998. Epizootic Ulcerative Syndrome (EUS). Technical Handbook. Aquatic Animal Health Research Institute, Bangkok. pp. 88.

Moniruzzaman, M. 2000. Investigation on disease of some small indigenous freshwater fishes of Bangladesh. M. S. Thesis, Department of Aquaculture, Bangladesh Agricultural University, Mymensingh. 80 pp.

Nessa, M. 2000. Disease investigation in walking catfish Clarias batrachus through histopathological techniques. M. S. Thesis, Department of Aquaculture, Bangladesh, Agricultural University, Mymensingh. 66 pp.

Roberts, R. J., Frerichs, G. N., Tonguthai, K. and Chainabut, S. 1994. Epizootic ulcerative syndrome of farmed and wild fishes. In: Muir, J. F. and R. J. Roberts (eds.). pp. 207-239. Recent Advances in Aquaculture V. Blackwell Science.

Roy, M. K., Ahmed, G. U., Akter, S. and Akter, N. 2006. Study of health condition of small indigenous freshwater fishes of Ailee beel, Mymensingh. Progress. Agric., 17(1): 201-209.

Ruksana, 1998. Monthly histopathological changes of walking catfish Clarias batrachus (Linn.). M. S. Thesis, Department of Aquaculture, Bangladesh Agricultural University, Mymensingh. 56 pp.

Sahoo, P. K., Sahu, B. B., Mohanty, J., Murjani, G. and Mukherjee, S. C. 1998. Ulcer diseases in catfish, Heteropneustes fossilis. Proceedings of the National Symposium on Technological Advancements in Fisheries and its impact on Rural Development. 5-7 December, 1995. pp. 147-152. School of Industrial Fisheries, Cochin University of Science and Technology, Cochin. 